\begin{tabular}{|c|c|c|c|}
\hline \multirow{3}{*}{$\begin{array}{r}\text { Case Reports in } \\
\text { ophthalmology }\end{array}$} & \multirow{2}{*}{\multicolumn{2}{|c|}{ Case Rep Ophthalmol 2014;5:392-399 }} & \multirow[b]{3}{*}{$\begin{array}{l}\text { Karger } \\
\text { Opengaccess }\end{array}$} \\
\hline & & & \\
\hline & $\begin{array}{l}\text { DOI: 10.1159/000369611 } \\
\text { Received: September 19, } 2014 \\
\text { Accepted: November 6, } 2014 \\
\text { Published online: November 26, } 2014\end{array}$ & $\begin{array}{l}\text { ( ) } 2014 \text { S. Karger AG, Basel } \\
\text { 1663-2699/14/0053-0392 } \$ 39.50 / 0 \\
\text { www.karger.com/cop }\end{array}$ & \\
\hline & $\begin{array}{l}\text { This is an Open Access article licensed u } \\
\text { NonCommercial } 3.0 \text { Unported license (C } \\
\text { the online version of the article only. Dist }\end{array}$ & $\begin{array}{l}\text { sof the Creative Commons Attribution } \\
\text { w.karger.com/OA-license), applicable t } \\
\text { ted for non-commercial purposes only }\end{array}$ & \\
\hline
\end{tabular}

\title{
Successful Treatment of Retinal Angiomatous Proliferation with Intravitreal Triamcinolone and Ranibizumab Injections in a 67-Year-Old Male
}

\author{
Adnaan Haq Bharat Kapoor Maharatnam Logendran Gopinath Reddy
}

Eye Department, Northampton General Hospital, Northampton, UK

\section{Key Words}

Retinal angiomatous proliferation - Neovascularisation - Triamcinolone - Ranibizumab .

Retina $\cdot$ Age-related macular degeneration

\begin{abstract}
A 67-year-old male who presented to the eye casualty department with deterioration in his vision was diagnosed with retinal angiomatous proliferation. After initial deterioration with ranibizumab intravitreal injections, we have demonstrated successful treatment and stabilised vision with ranibizumab and a single intravitreal triamcinolone injection. Stringent follow-up and top-up ranibizumab injections have stabilised his vision and have shown foveal improvement on optical coherence tomography imaging.

(c) 2014 S. Karger AG, Basel
\end{abstract}

\section{Introduction}

Retinal angiomatous proliferation (RAP) is a form of retinal-choroidal neovascularisation within the wet age-related macular degeneration (AMD) category, characterised by intraretinal capillary proliferation, subretinal neovascularisation and a serous/vascularised pigment epithelial detachment including a retinal-choroidal anastomosis. RAP has been proved to be notoriously difficult to treat, with very few case reports and published articles on successful treatment. We describe the case of a 67-year-old male with RAP undergoing successful treatment with stabilised visual acuity. 


\section{Background}

RAP is a distinct form of choroidal neovascularisation first recognised as a separate entity in 1992 as a deep retinal vascular anomalous complex [1]. The concept was modified in 2001 when the term 'RAP' was first used, describing a complex pathology of retinal choroidal anastomoses with/without pigment epithelial detachments.

RAP can be described as a 3-stage local vasogenic sequence. Stage 1 describes the intraretinal proliferation of capillaries in the paramacular region. This neovascularisation extends posteriorly, leading to subretinal neovascularization, which may lead to a neurosensory retinal detachment as well as to an associated serous pigment epithelial detachment. This is classified as stage 2 . Stage 3 occurs when neovascularisation extends into the choroidal circulation, sometimes in association with a vascularised pigment epithelial detachment. During this process, a connection between the retinal and choroidal circulation may develop, leading to a retinal-choroidal anastomosis.

Reports have shown that between 8 and 22\% [2] of cases previously diagnosed as exudative AMD are RAP. There is a distinct correlation between age and the development of RAP, with a median patient age of 80 years. Females are at a higher risk of developing RAP, with one report claiming a $90 \%$ tendency towards the female gender.

Unfortunately, due to the nature of the disease, rates of second-eye RAP are high. Up to $80 \%$ of fellow eyes develop neovascularisation after 1 year, and $100 \%$ of patients will have developed some form of neovascularisation before 3 years since first eye diagnosis.

While most published data have focused on intravitreal ranibizumab injections as the mainstay of treatment, we discuss the case of a patient with RAP undergoing successful treatment with intravitreal ranibizumab and intravitreal triamcinolone acetonide (IVTA).

\section{Case Report}

A 67-year-old male presented to the eye casualty department in December 2008 with a 1-week history of distorted vision in his left eye. His past ocular history was significant in that he had a disciform scar in his right eye leaving him with hand movement vision. He has also been under the care of the medical retinal consultant since January 2008 with a left occult choroidal neovascular membrane for which he had received 5 intravitreal injections of bevacizumab.

His past medical history included peripheral vascular disease, essential hypertension, impaired glucose tolerance, early dementia and depression.

On examination at the casualty department, his visual acuity was $6 / 38+2$ in the left eye with microaneurysms at the fovea with minimal oedema. A fundus fluorescein angiogram (FFA) and optical coherence tomography (OCT) were requested, which revealed the following (fig. 1, fig. 2).

The patient was seen in at clinic as a matter of urgency. A decision was made with the patient to start intravitreal ranibizumab due to the presence of only one functioning eye. Bevacizumab was stopped, and treatment was initiated a week later. The patient showed significant improvement after the first 3 injections, and his vision remained stable. Figure 3 shows his OCT image.

The patient received a total of 10 intravitreal ranibizumab injections within the first year, with stable vision at 6/24 (40 letters). However, in May 2010, during routine follow-up, the patient presented to the Age-Related Macular Degeneration (ARMD) clinic complaining 
Haq et al:: Successful Treatment of Retinal Angiomatous Proliferation with Intravitreal Triamcinolone and Ranibizumab Injections in a 67-Year-Old Male

of reduced vision. Visual acuity was $6 / 120+4$ (8 letters), and his OCT scans are shown in fig. 4. A repeat FFA was organised immediately (fig. 5).

The decision was made to treat the patient with IVTA, and the patient was given a single IVTA injection. The patient was given the IVTA injection in the first week of June 2010. During the subsequent visits, an immediate improvement in vision was noted as well as improvements in his OCT imaging. His visual acuity improved to 6/48 (25 letters) at the first visit and remained stable for the following 2 months. His OCT scan 1 month after IVTA is shown in fig. 6.

He required no further intravitreal triamcinolone injections, and ranibizumab injections were continued based on OCT appearances on a monthly basis. Since the intravitreal triamcinolone injection, he has received a total of 7 intravitreal ranibizumab injections to the left eye over a 4-year period based on his OCT appearances, with the last injection in October 2013. His vision fluctuates on a monthly basis but it has remained between $6 / 48+3(28$ letters) and 6/30 - 1 (34 letters). OCT images at the 1-, 2-, 3- and 4-year follow-up are shown in fig. 7.

Currently, the patient is still under follow-up at the ARMD clinics. His right eye shows no signs of RAP and is being monitored with OCT imaging. As the patient had an almost immediate improvement with IVTA injection based on vision and intra-retinal fluid, we are able to confirm the inflammatory nature of RAP and the effects of IVTA.

\section{Discussion}

While there has been little research into RAP as a separate entity (often treated similar to other types of proliferative AMD), the mainstay of treatment in most published articles was intravitreal ranibizumab injections. Although there have been some favourable results using ranibizumab alone, as shown by the study of Inoue et al. [3], there has also been evidence indicating that IVTA can be beneficial in treating RAP.

Due to the inflammatory nature of RAP, IVTA was used by the consultant after previous studies had proved the efficacy of IVTA in combination with other therapies. The majority of published studies have combined IVTA treatment with photodynamic therapy (PDT), including some mixed results. In 2012, the study of Rouvas et al. [4] showed an anatomical improvement (geographic atrophy) in patients with IVTA and PDT treatment, suggesting, along with the study of Mendis et al. [5], that IVTA and PDT can be considered as treatment for RAP. However, this was contradicted by the study of Saito et al. [6], highlighting antivascular endothelial growth factor and PDT therapy as a more favourable option.

To our knowledge, there has been no evidence to suggest using a combination of IVTA and ranibizumab injections for the treatment of RAP. While most studies have focused on using either treatment in combination with PDT, there have been no published data on the combined use of anti-vascular endothelial growth factor and IVTA treatments. As this case report demonstrates, 1 dose of IVTA with top-up injections of ranibizumab including a comprehensive follow-up cannot only stabilise and improve vision, but also improve the geographic appearance of the macula. 
Haq et al:: Successful Treatment of Retinal Angiomatous Proliferation with Intravitreal Triamcinolone and Ranibizumab Injections in a 67-Year-Old Male

\section{Conclusion}

The use of combined intravitreal ranibizumab and IVTA for RAP has never been published. We have successfully demonstrated a positive outcome in combined intravitreal treatment for this difficult condition.

\section{References}

1 Yannuzzi LA, Negrao S, Iida T, Carvalho C, Rodriguez-Coleman H, Slakter J, Freund KB, Sorenson J, Orlock D, Borodoker N: Retinal angiomatous proliferation in age-related macular degeneration. Retina 2001;21:416434.

2 Marticorena J, Di Leva V, Cennamo GL, de Crecchio G: Retinal angiomatous proliferation. Curr Drug Targets 2011;12:199-205.

-3 Inoue M, Arakawa A, Yamane S, Kadonosono K: Long-term results of intravitreal ranibizumab for the treatment of retinal angiomatous proliferation and utility of an advanced RPE analysis performed using spectral-domain optical coherence tomography. Br J Ophthalmol 2014;98:956-960.

4 Rouvas AA, Papakostas TD, Vavvas D, Vergados I, Moschos MM, Kotsolis A, Ladas ID: Intravitreal ranibizumab, intravitreal ranibizumab with PDT, and intravitreal triamcinolone with PDT for the treatment of retinal angiomatous proliferation: a prospective study. Retina 2009;29:536-544.

5 Mendis R, Leslie T, McBain V, Lois N: Combined therapy for retinal angiomatous proliferation with intravitreal triamcinolone and argon laser photocoagulation. Br J Ophthalmol 2008;92:1154-1156.

-6 Saito M, Shiragami C, Shiraga F, Kano M, Iida T: Comparison of intravitreal triamcinolone acetonide with photodynamic therapy and intravitreal bevacizumab with photodynamic therapy for retinal angiomatous proliferation. Am J Ophthalmol 2010;149:472-481.

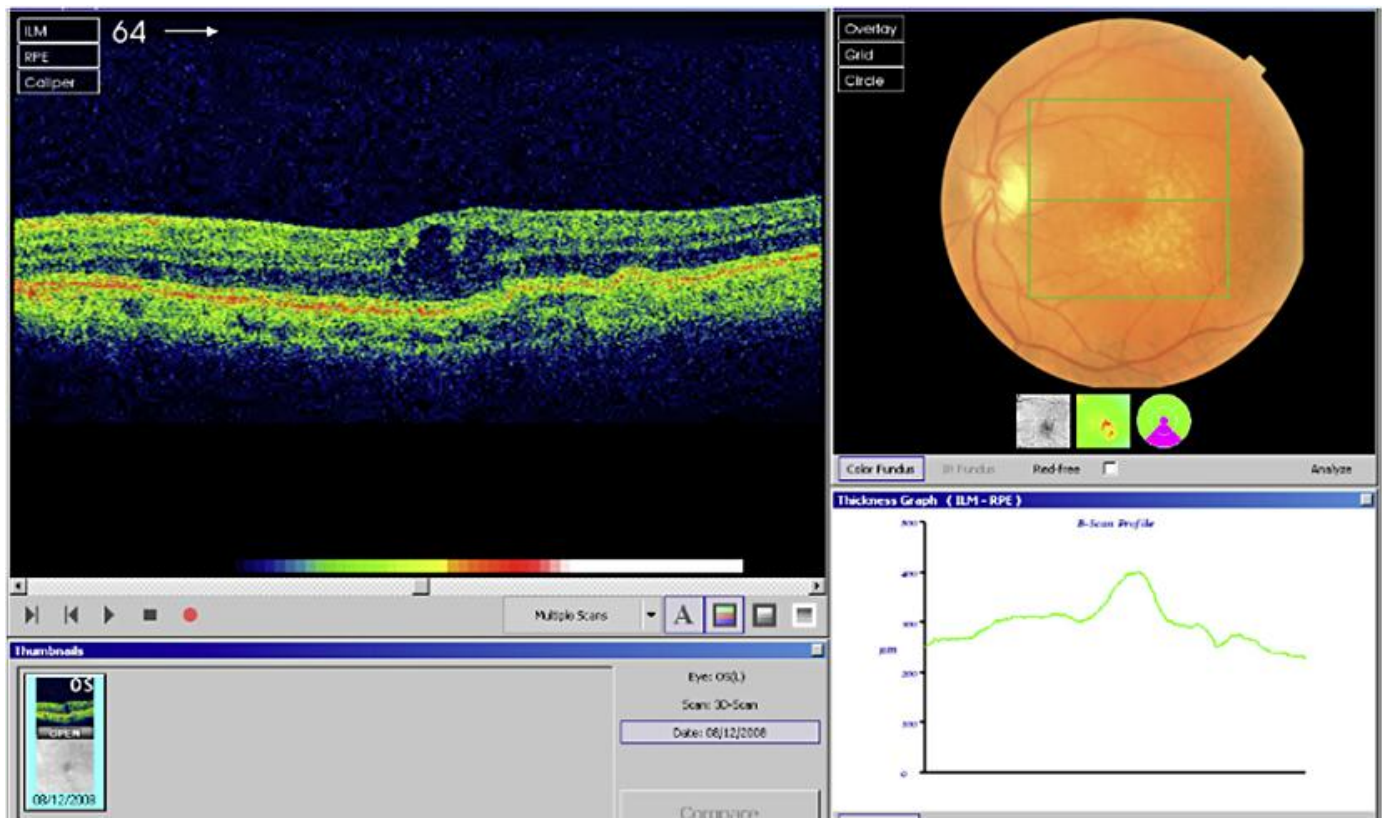

Fig. 1. OCT of the patient in December 2008 showing significant intraretinal fluid and a perifoveal thickness of $299 \mu \mathrm{m}$. 


\section{Case Reports in Ophthalmology}

\begin{tabular}{l|l}
\hline Case Rep Ophthalmol 2014;5:392-399 \\
\hline DOI: 10.1159/000369611 & $\begin{array}{l}\text { @ 2014 S. Karger AG, Basel } \\
\text { www.karger.com/cop }\end{array}$ \\
\hline
\end{tabular}

Haq et al.: Successful Treatment of Retinal Angiomatous Proliferation with Intravitreal Triamcinolone and Ranibizumab Injections in a 67-Year-Old Male

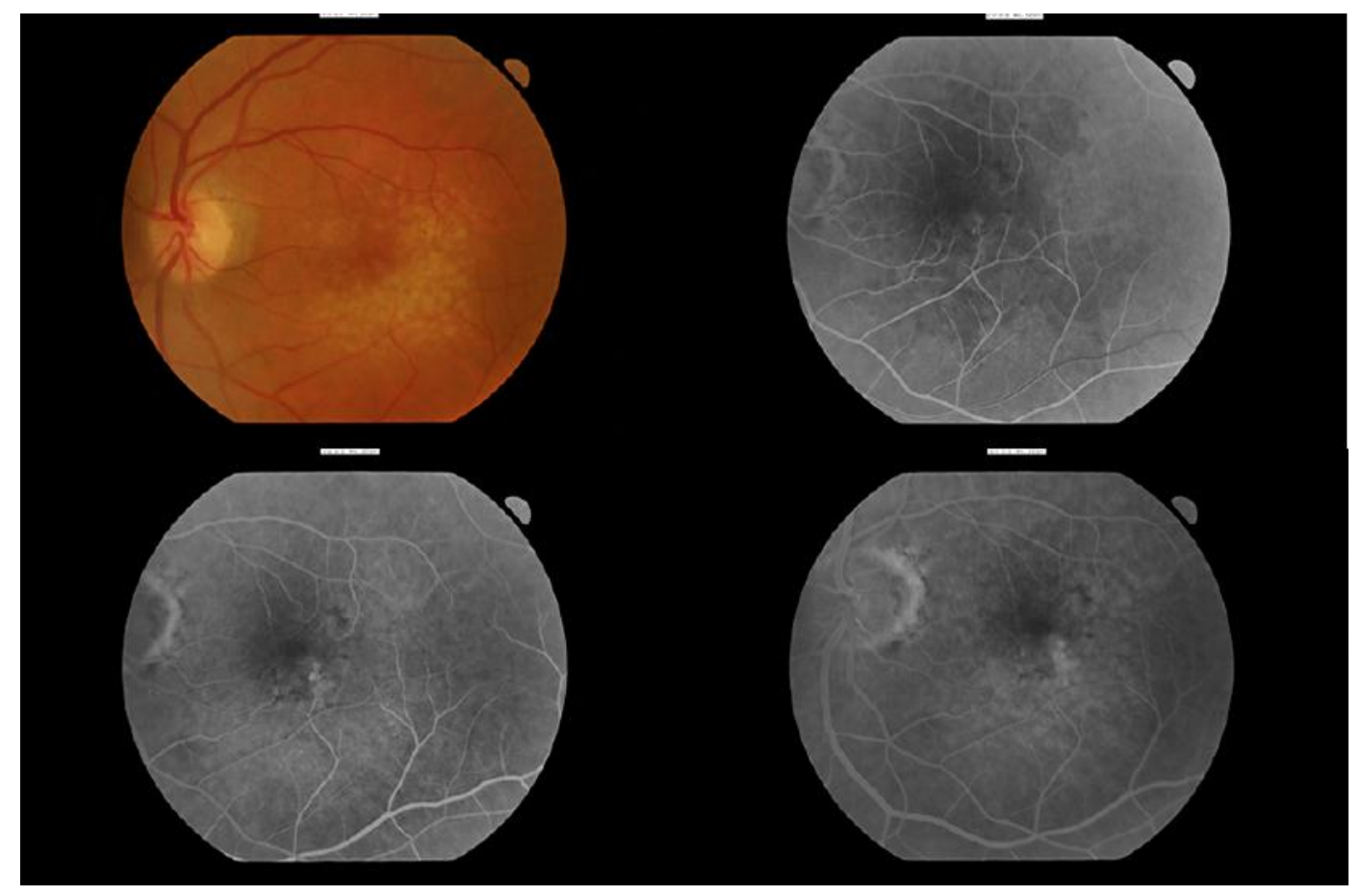

Fig. 2. FFA of the patient in December 2008. The images display pronounced retinal telangiectasia.

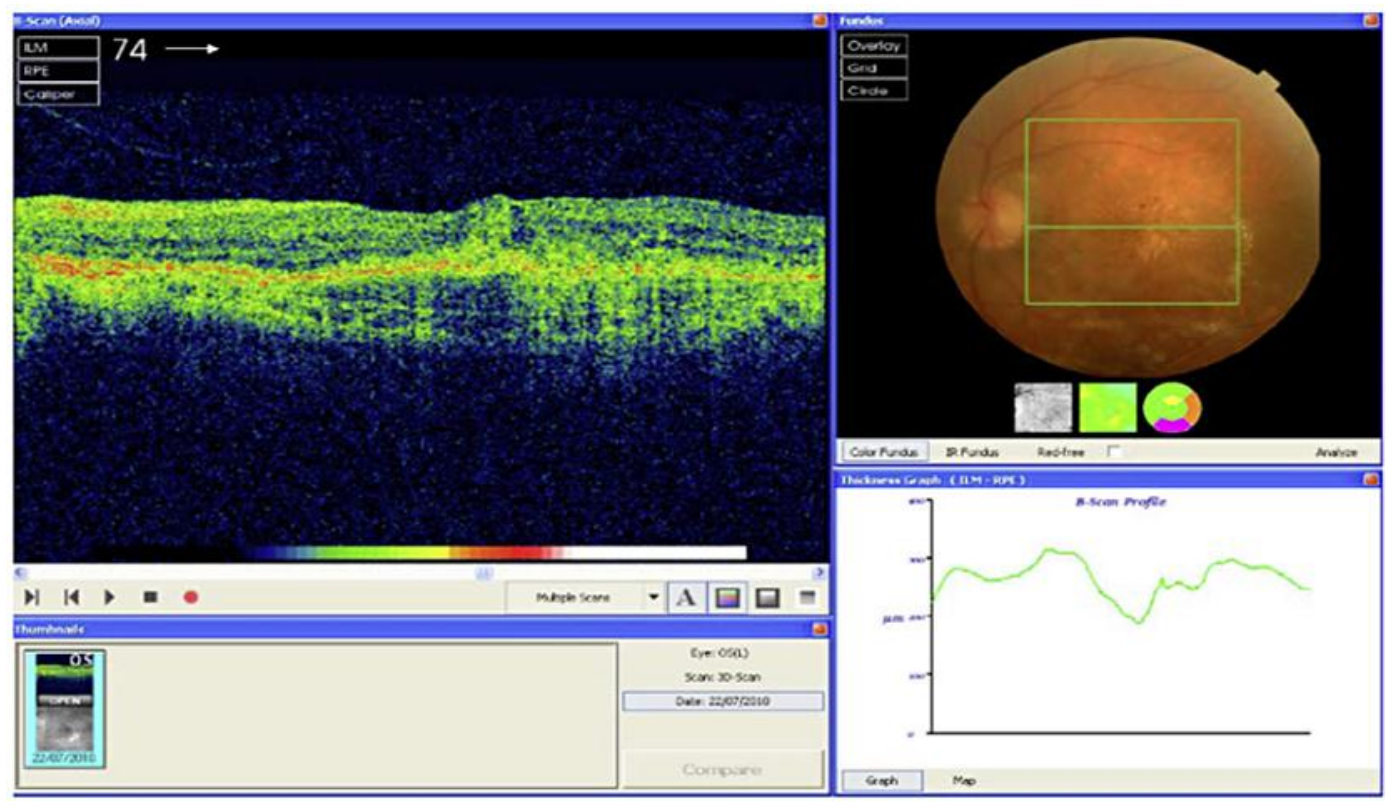

Fig. 3. OCT image from March 2009 showing dry fovea with a perifoveal thickness of $238 \mu \mathrm{m}$. 
Case Reports in

Ophthalmology
Case Rep Ophthalmol 2014;5:392-399

DOI: $10.1159 / 000369611$

www.karger.com/cop

Haq et al.: Successful Treatment of Retinal Angiomatous Proliferation with Intravitreal Triamcinolone and Ranibizumab Injections in a 67-Year-Old Male

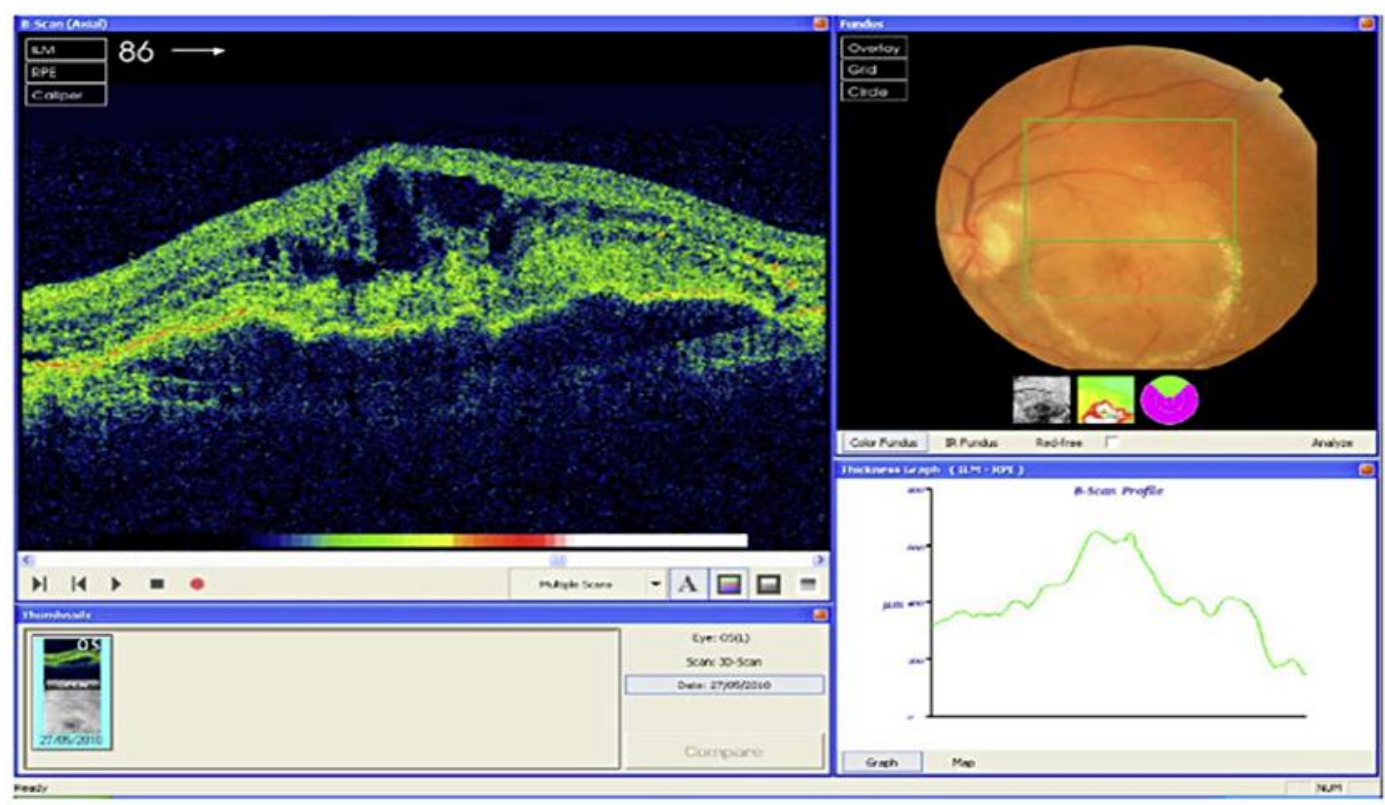

Fig. 4. OCT image from May 2010 showing a large pigment epithelial detachment with intraretinal fluid and exudates as well as a perifoveal thickness of $890 \mu \mathrm{m}$. 
Case Reports in

Ophthalmology
Case Rep Ophthalmol 2014;5:392-399

DOI: $10.1159 / 000369611$

Haq et al: Successful Treatment of Retinal Angiomatous Proliferation with Intravitreal

Triamcinolone and Ranibizumab Injections in a 67-Year-Old Male

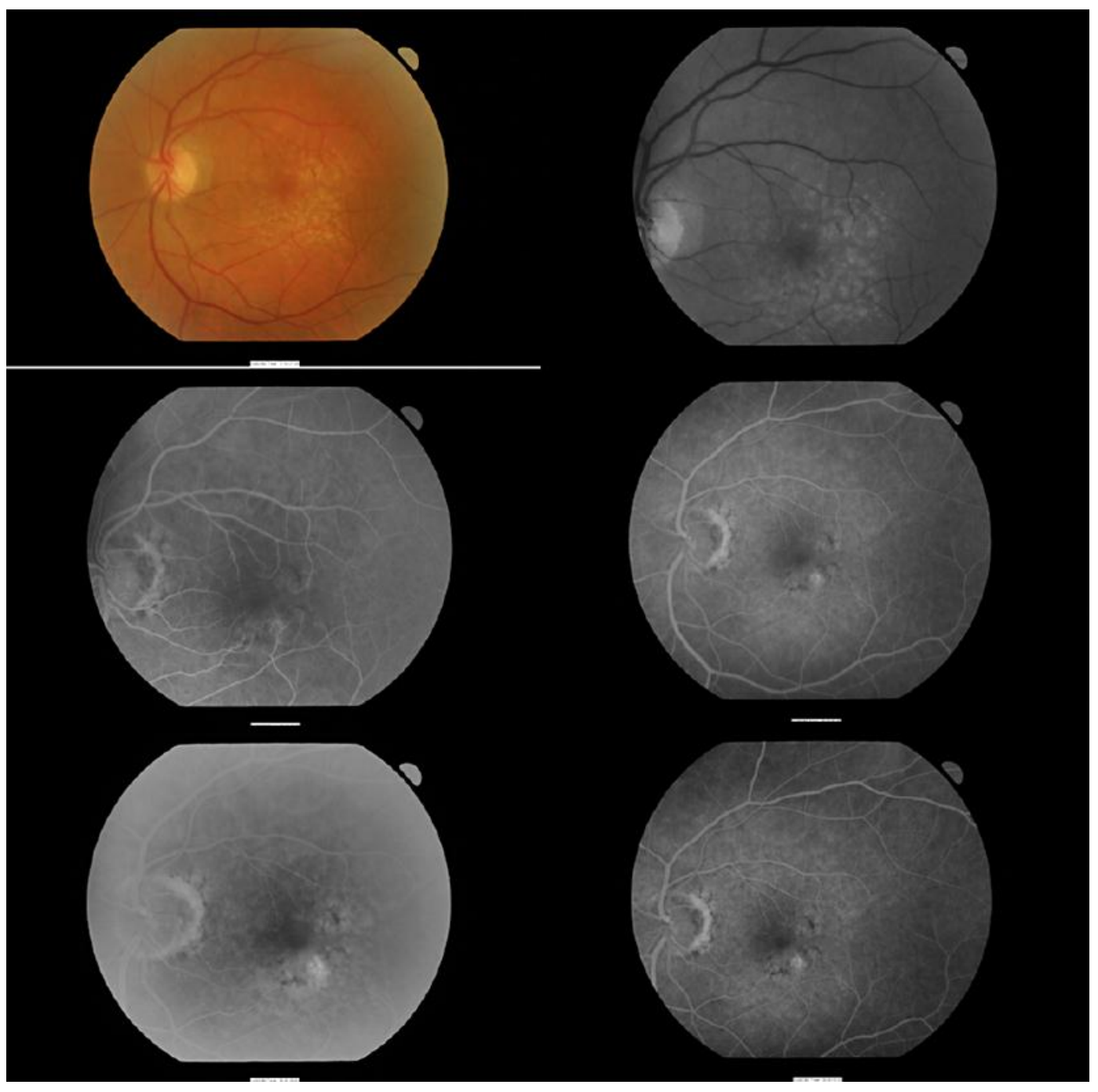

Fig. 5. Repeat FFA from May 2010. Image 3 shows prominent retinal vessels and RAP. 


\section{Case Reports in Ophthalmology}

\begin{tabular}{l|l}
\hline Case Rep Ophthalmol 2014;5:392-399 \\
\hline DOI: 10.1159/000369611 & $\begin{array}{l}\text { ○ 2014 S. Karger AG, Basel } \\
\text { www.karger.com/cop }\end{array}$ \\
\hline
\end{tabular}

Haq et al.: Successful Treatment of Retinal Angiomatous Proliferation with Intravitreal Triamcinolone and Ranibizumab Injections in a 67-Year-Old Male

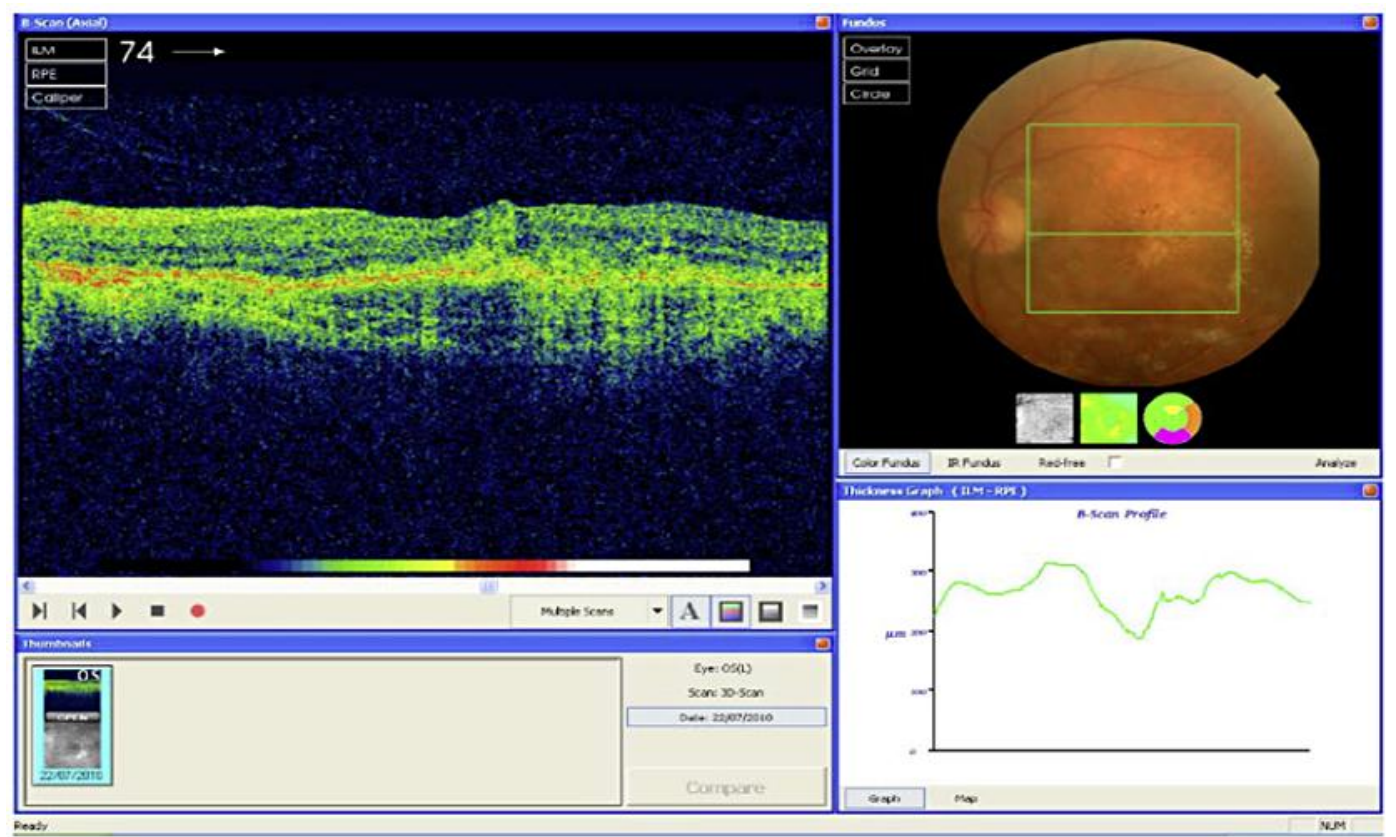

Fig. 6. Repeat OCT 1 month after intravitreal triamcinolone injection showing complete resolution of the intraretinal fluid as well as exudates which are beginning to settle.

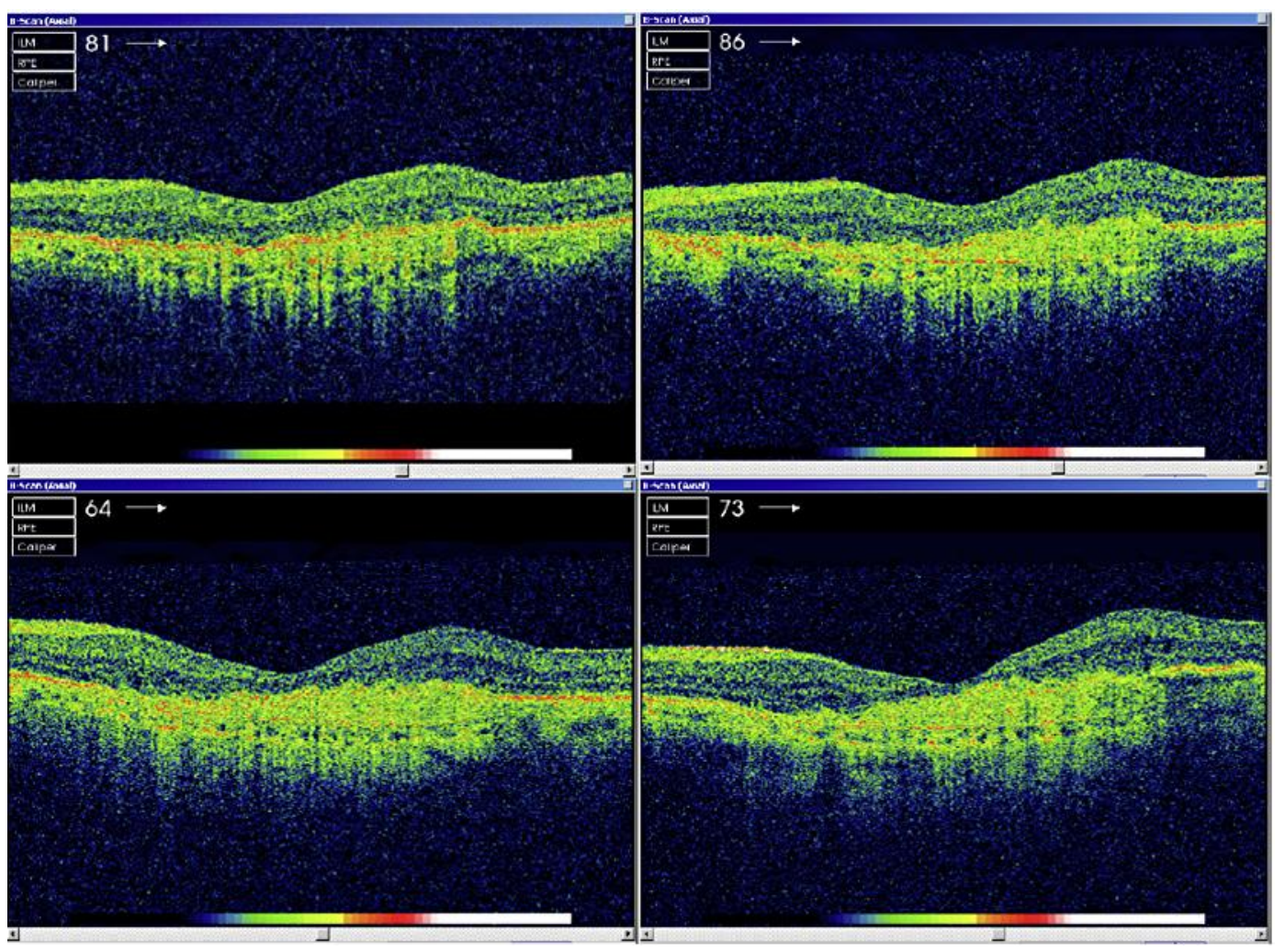

Fig. 7. Series of OCT images: top left, July 2011; top right, July 2012; bottom left, June 2013, and bottom right, March 2014. Complete resolution of the intraretinal fluid. 